\title{
Evaluation of Auditory Brain Stems Evoked Response in Newborns With Pathologic Hyperbilirubinemia in Mashhad, Iran
}

\author{
Tooba Okhravi ${ }^{1,2}$; Saeedeh Tarvij Eslami ${ }^{3,3}$; Ali Hushyar Ahmadi ${ }^{4}$; Hossain Nassirian ${ }^{3}$; Reza \\ Najibpour ${ }^{1}$ \\ ${ }^{1}$ Student Research Committee, Tehran Medical Sciences Branch, Islamic Azad University, Tehran, IR Iran \\ ${ }_{\mathrm{ABR}}^{2}$ Center, Mashhad Branch, Islamic Azad University, Mashhad, IR Iran \\ 3 Department of Pediatrics, Tehran Medical Sciences Branch, Islamic Azad University, Tehran, IR Iran \\ ${ }^{4}$ Mashhad Branch, Islamic Azad University, Mashad, IR Iran \\ ${ }^{*}$ Corresponding Author: Saeedeh Tarvij Eslami, Department of Pediatrics, Islamic Azad University, Tehran Medical Sciences Branch, Tehran, IR Iran. Tel: +98-9128444226, Fax: +98- \\ 2189787379, E-mail:s_tarvij@yahoo.com
}

Received: February 7, 2014; Revised: April 7, 2014; Accepted: May 3, 2014

\begin{abstract}
Background: Neonatal jaundice is a common cause of sensorneural hearing loss in children.
Objectives: We aimed to detect the neurotoxic effects of pathologic hyperbilirubinemia on brain stem and auditory tract by auditory brain stem evoked response (ABR) which could predict early effects of hyperbilirubinemia.

Patients and Methods: This case-control study was performed on newborns with pathologic hyperbilirubinemia. The inclusion criteria were healthy term and near term (35 - 37 weeks) newborns with pathologic hyperbilirubinemia with serum bilirubin values of $\geq 7 \mathrm{mg} / \mathrm{dL}, \geq 10 \mathrm{mg} / \mathrm{dL}$ and $\geq 14 \mathrm{mg} / \mathrm{dL}$ at the first, second and third-day of life, respectively, and with bilirubin concentration $\geq 18 \mathrm{mg} / \mathrm{dL}$ at over 72 hours of life. The exclusion criteria included family history and diseases causing sensorineural hearing loss, use of auto-toxic medications within the preceding five days, convulsion, congenital craniofacial anomalies, birth trauma, preterm newborns $<35$ weeks old, birth weight $<1500 \mathrm{~g}$, asphyxia, and mechanical ventilations for five days or more. A total of 48 newborns with hyperbilirubinemia met the enrolment criteria as the case group and 49 healthy newborns as the control group, who were hospitalized in a university educational hospital (22 Bahaman), in a north-eastern city of Iran, Mashhad. ABR was performed on both groups. The evaluated variable factors were latency time, inter peak intervals time, and loss of waves.

Results: The mean latencies of waves I, III and V of ABR were significantly higher in the pathologic hyperbilirubinemia group compared with the controls $(\mathrm{P}<0.001)$. In addition, the mean interpeak intervals (IPI) of waves I-III, I-V and III-V of ABR were significantly higher in the pathologic hyperbilirubinemia group compared with the controls $(\mathrm{P}<0.001)$. For example, the mean latencies time of wave I was significantly higher in right ear of the case group than in controls $(2.16 \pm 0.26 \mathrm{vs} .1 .77 \pm 0.15$ milliseconds, respectively) $(\mathrm{P}<0.001)$.

Conclusions: Pathologic hyperbilirubinemia causes acute disorder on brain stem function; therefore, early diagnosis of neonatal jaundice for prevention of bilirubin neurotoxic effects is essential. As national neonatal hearing screening in not yet established in Iran, we recommend performing ABR for screening of bilirubin neurotoxicity in all cases with hyperbilirubinemia.
\end{abstract}

Keywords:Newborn; Bilirubin; Hyperbilirubinemia; Auditory Brain Stem Evoked Response

\section{Background}

Hyperbilirubinemia is a common problem in newborns and one of the most important problems in Asian newborns. Yellow discoloration of sclera, skin and mucous membrane is the sign of hyperbilirubinemia. The yellow color results from the accumulation of unconjugated, nonpolar, lipid-soluble bilirubin pigment in the skin. Jaundice is observed during the first week of life in approximately $60 \%$ of term infants and $80 \%$ of preterm infants. As bilirubin is soluble in lipid, it could pass across the blood brain barrier and distribute in the brain (1).

Indirect bilirubin, the main cause of neonatal jaundice, is strongly neurotoxic for underdevelopment neural system, especially when the indirect bilirubin concentration exceeds the albumin binding capacity. Unconjugated bilirubin binds the phospholipids of neuronal plasma membranes as well as the phospholipids of subcellular organelles membrane, which leads to cell oxygen deprivation, energy metabolism impairment, and cell death. The phenomenon of deposited indirect bilirubin in basal ganglia as well as in the vestibule-cochlear nucleus causes a neurological syndrome called kernicterus as well as sensorineural hearing loss. Kernicterus continues to be reported worldwide in otherwise healthy term infants (2-5).

Unconjugated bilirubin level more than $25 \mathrm{mg} / \mathrm{dL}$ affects the intelligence quotient (IQ) of infants (1) and leads to lower scores on achievement and verbal IQ 
tests. The most common causes of pathologic indirect hyperbilirubinemia are as follows:

1) Increased bilirubin production due to hemolytic diseases which includes immune-mediated hemolysis (ABO or Rh incompatibility), inherited red cell membrane defects (spherocytosis), erythrocyte enzymatic defects (glucose-6-phosphate dehydrogenase (G6PD) deficiency), and sepsis.

2) Decreased clearance (Crigler-Najjar and Gilbert's syndromes).

$3)$ Increased enterohepatic circulation such as breast feeding jaundice (6). The calculated prevalence of Gilbert's syndrome was 19.1\% in a study in Iran (7).

Structural changes to facilitate a system-based approach should include predischarged bilirubin management, follow-up bilirubin management, lactational support, and nutritional management (8). Hyperbilirubinemia at neonatal period is one of the major deteriorating factors of the auditory system; if left untreated, it leads to cerebral damage (9).

Early detection of hearing loss and treatment in primary stages is important. Even a mild hearing loss can cause significant speech disorder and hold up development of communication skills (10). Currently, the most sensitive means of assessing neurotoxicity may be auditory brain stem evoked response (ABR), which shows the predictable early effects of bilirubin toxicity (5).

In $\mathrm{ABR}$, diagnosis is based on the evaluation of latencies of waves I, III and V and inter-peak-interval of waves I-III, I-V and III-V. ABR is the most sensitive test for detecting retrocochlear hearing loss (11). This test needs the patient remain silent during the trial. In this test, electrodes attached to the scalp and mastoid processes cause electrical response by audio stimulation (12).

$A B R$ evaluates the important waves of the auditory pathways which include: wave I, related to the primary part of the auditory nerve, near the cochlea; wave II, related to the intracranial part of the eight nerves near the brain stem and cochlear nucleus and pons; wave III, related to the superior olivary complex; wave IV, related to the middle and superior parts of pons; wave $\mathrm{V}$, related to the lateral lemniscus above the pons and inferior lemniscus of the midbrain (11). Physical characteristics of ABR vary greatly with age, reflecting the evolution of cochlear and neural pathways. In human, beginning the waves of brain stem response is at the third trimester of pregnancy and the earliest possible time of recording these waves is in premature infants with a gestational age of 25 weeks $( \pm 6)(12,13)$.

\section{Objectives}

As jaundice is one of the most important risk factors for newborns' hearing loss and national neonatal hearing screening in not yet established in Iran, the aim of this study was evaluation of ABR in healthy newborns with pathologic hyperbilirubinemia, comparing it with
ABR in healthy newborns without hyperbilirubinemia and giving emphasize to performing hearing screening in newborns with hyperbilirubinemia.

\section{Patients and Methods}

This case-control study included 97 newborns hospitalized in a university educational general hospital (22 Bahaman), from 2011 to 2012, in a north-eastern city of Iran, Mashhad. The hospital is related to the Medical Faculty of Islamic Azad University, Mashhad Branch. The sample size by easy sampling was calculated based on the following formula.

Equation 1. $\quad n=\frac{Z^{2} \mathrm{P}(1-\mathrm{P})}{e^{2}} 97$

\section{$\mathrm{Z}=1.5, \mathrm{P}=0.5, \mathrm{e}=10 \%$}

The inclusion criteria were: healthy term newborns (more than 37 weeks old) and near term newborn (35-37 weeks old), healthy newborns with pathologic hyperbilirubinemia with serum bilirubin value of $\geq 7 \mathrm{mg} / \mathrm{dL}$ at the first day of life, $\geq 10 \mathrm{mg} / \mathrm{dL}$ at the second day of life, $\geq 14 \mathrm{mg} / \mathrm{dL}$ at the third day of life, and $\geq 18 \mathrm{mg} / \mathrm{dL}$ at over 72 hours of life. These selections were based on the medium risk curve for hyperbilirubinemia in Bhutani guideline (14).

The exclusion criteria included reports of one or more of the following: any disease, causing sensorineural hearing loss (intrauterine infection, sepsis, meningitis), family history of sensorineural hearing loss, use of auto-toxic medications within the preceding five days, convulsion, congenital craniofacial anomalies, birth trauma (intracranial hemorrhage), preterm newborns (less than 35 weeks old), birth weight less than $1500 \mathrm{~g}$, asphyxia (Apgar scores less than 7 during the first five minutes), mechanical ventilations for five days or more.

A data collection form was designed for the study. Mothers and newborns were admitted to the study after screening. A total of 52 newborns with hyperbilirubinemia met the enrolment criteria as case group, one newborn with exchange transfusion became ill and was excluded and three parents refused ABR. Therefore, four newborns in the case group were excluded from the study; 9 of the 58 newborns in the control group were excluded because their parents refused ABR.

Totally, 97 newborns (194 ears) were enrolled in the study. The case group included 48 healthy newborns with pathologic hyperbilirubinemia and the control group included 49 newborns without pathologic hyperbilirubinemia. Phototherapy was applied continuously for the case group and discontinued at serum bilirubin value of $11 \mathrm{mg} / \mathrm{dL}$. ABR was performed on both groups at the time of discharge from the hospital. All changes of ABR were analyzed by a neurologist. The recording machine for ABR was Toennies (Germany). 
Okhravi Tet al.

The sweep velocity was 10 millisecond. Click acoustic stimuli with a click rate of $10 /$ second alternating in polarity were presented by an earphone to each ear alternately at an intensity of $70 \mathrm{~dB}$ hearing level. The electrical activities were filtered and averaged to 2000 responses.

The major variable factors were:

1) Mean latency time of waves I, III and V.

2) Inter peak interval of waves I-III, I-V and III-V.

3) Absence of waves.

Variables like gender, birth weight and Apgar score in one and five minutes, maternal age, number and type of delivery, and other variables were considered as well.

\subsection{Ethical Considerations}

This study was conducted according to the guidelines of Helsinki, the Guidelines for the Ethical Conduct of Medical Research Involving Children, revised by the Royal College of Pediatrics and Child Health: Ethics Advisory Committee. We considered the Committee on Publication Ethics (COPE) guidelines as well. The study was approved by the Institutions' Ethical Committee. There was no moral inconsideration about the study method. Therefore, all the cooperators and parents were explained about the mentioned method. We received written informed consent from all the parents in 2011.

Based on normal distribution (K-S normality test result), descriptive statistical analyses such as central tendency and distribution parameters and analytical statistics tests such as independent sample t-test, chi square, and Fisher's exact test were performed for description and analysis of the obtained data. The data were analyzed with P Value $<0.05$ through SPSS 18 software.

\section{Results}

Of 97 newborns who met the enrolment criteria and participated in the study, 48 (49.4\%) were male and 49 (50.5\%) were female. The case group included 48 newborns ( 27 males and 21 females) and there were 49 newborns ( 21 males and 28 females) in the control group.

There was no significant statistical difference regarding gender, maternal age, number and type of delivery, birth weight, and Apgar score in one and five minutes between the two groups. In the case group, weight of $58.3 \%$ of the infants was more than $2500 \mathrm{~g}$ and $41.7 \%$ were 1500 - 2500 g. Furthermore, in the case group, $72.9 \%$ of newborns were term and $27.1 \%$ were near term.

The mean age of newborns was $11.5 \pm 3.92$ days. The average bilirubin level was $19.5 \pm 3.84$ and $6.38 \pm 0.78$ $\mathrm{mg} / \mathrm{dL}$ before and after the phototherapy, respectively (Table 1).

In evaluation of the risk factors predisposing hyperbilirubinemia, the most common ones were idiopathic or breast feeding in $77 \%, \mathrm{ABO}$ and $\mathrm{Rh}$ incompatibility in $16.7 \%$, and G6PD deficiency in $6.3 \%$ of cases.
The latencies and inter-peak intervals of different waves in cases and control groups (both right and left ears separately) are shown in Table 2 . The mean latencies time of wave I of ABR was significantly higher in right ears of the case group than that of the control group $(2.16 \pm 0.26$ vs. $1.77 \pm 0.15$ milliseconds, respectively, Figure 1$)(\mathrm{P}<0.001)$. The mean latencies time of wave I of ABR was significantly higher in left ears of the case group than that of the control group $(2.21 \pm 0.31$ vs. $1.89 \pm 0.18$ milliseconds, respectively) $(\mathrm{P}<0.001)$. The mean latencies time of wave III in right ears of the case group (4.29 \pm 0.34$)$ was significantly higher than that of the control group (3.73 \pm 0.27 milliseconds) $(\mathrm{P}<$ 0.001). The mean latencies time of wave III in left ears of the case group $(4.36 \pm 0.34)$ was significantly higher than that of the control group (3.79 \pm 0.27 milliseconds, Figure 2) $(\mathrm{P}<0.001)$. The mean latencies time of wave $\mathrm{V}$ was significantly higher in right ears of the case group than in that of the control group ( $6.36 \pm 0.37$ vs. $5.60 \pm$ 0.25 milliseconds, respectively, Figure 3$)(\mathrm{P}<0.001)$. The mean latencies time of wave $\mathrm{V}$ was significantly higher in left ears of the case group than that of the control group (6.44 \pm 0.39 vs. $5.71 \pm 0.28$ milliseconds, respectively) $(\mathrm{P}<0.001)$. The mean inter-peak-intervals (IPI) of waves I-V of ABR in right ears of the case group was 4.20 \pm 0.19 and in control group it was $3.83 \pm 0.28$ milliseconds (Figure 4$)(\mathrm{P}<0.001)$, and the IPI of waves I-V in left ears of the case group was $4.18 \pm 0.37$ and in control group it was $3.81 \pm 0.28$ milliseconds $(P<0.001)$. The IPI of waves I-III in right ears of the case group (2.13 \pm 0.19$)$ was significantly higher than that of the control group (1.95 \pm 0.27 milliseconds) (Figure 5$)(P<0.001)$. The IPI of wave I-III in left ear of the case group ( $2.15 \pm 0.21)$ was significantly higher than that of the control group (1.89 \pm 0.31 milliseconds) $(\mathrm{P}<0.001)$. The IPI of waves III-V in right ears of the case group was $2.07 \pm 0.17$ and in control group it was $1.86 \pm 0.34$ milliseconds $(P=0.001)$. The IPI of waves III-V in left ears of the case group was $2.07 \pm$ 0.22 and in control group it was $1.92 \pm 0.33$ milliseconds (Figure 6) $(\mathrm{P}=0.013)$.

\begin{tabular}{|c|c|}
\hline Average Bilirubin Levels, mg/dL & Mean \pm SD \\
\hline Bilirubin level before phototherapy & $19.5 \pm 3.48$ \\
\hline Bilirubin level at the first day of treatment & $3.43 \pm 17.48$ \\
\hline Bilirubin level at the second day of treatment & $15.17 \pm 3.04$ \\
\hline Bilirubin level at the third day of treatment & $12.14 \pm 2.57$ \\
\hline Bilirubin level at the fourth day of treatment & $9.48 \pm 1.45$ \\
\hline Bilirubin level at the fifth day of treatment & $6.74 \pm 0.91$ \\
\hline $\begin{array}{l}\text { Bilirubin level after stopping the } \\
\text { phototherapy }\end{array}$ & $6.38 \pm 0.78$ \\
\hline
\end{tabular}


Table 2. Latencies of Various Waves and Inter-Peak Intervals at $70 \mathrm{~dB}$ in Case and Control Groups

\begin{tabular}{lcclc}
\hline Variables & \multicolumn{3}{c}{ Mean \pm SD } & \multicolumn{2}{c}{ PValue } \\
\hline $\begin{array}{l}\text { Latency, mil- } \\
\text { lisecond }\end{array}$ & Right Ear & Left Ear & Right & Left \\
\hline I & & & & \\
\hline Control & $1.77 \pm 0.15$ & $1.89 \pm 0.18$ & $<0.001$ & $<0.001$ \\
\hline Case & $2.16 \pm 0.26$ & $2.21 \pm 0.31$ & & \\
\hline III & & & & \\
\hline Control & $3.73 \pm 0.27$ & $3.79 \pm 0.27$ & $<0.001$ & $<0.001$ \\
\hline Case & $4.29 \pm 0.34$ & $4.36 \pm 0.34$ & & \\
\hline V & & & & \\
\hline III-V & & & & \\
\hline Control & & & & \\
\hline Control & $5.60 \pm 0.25$ & $5.71 \pm 0.28$ & $<0.001$ & $<0.001$ \\
\hline Case & $6.36 \pm 0.37$ & $6.44 \pm 0.39$ & & \\
\hline Control & & & & \\
\hline Case & & & & \\
\hline
\end{tabular}

Figure 1. Comparing the Mean Latencies Time of Wave I of Auditory Brain Stem Evoked Response Between Right Ears of the Case Group and That of the Control Group

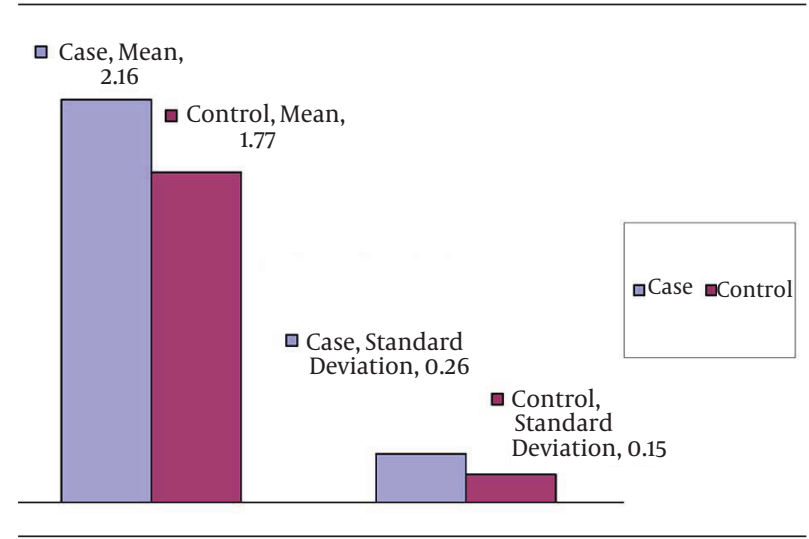

$\mathrm{T}=0.16, \mathrm{df}=95, \mathrm{P}<0.001$
Figure 2. Comparing the Mean Latencies Time of Wave III Between Left Ears of the Case Group and That of the Control Group

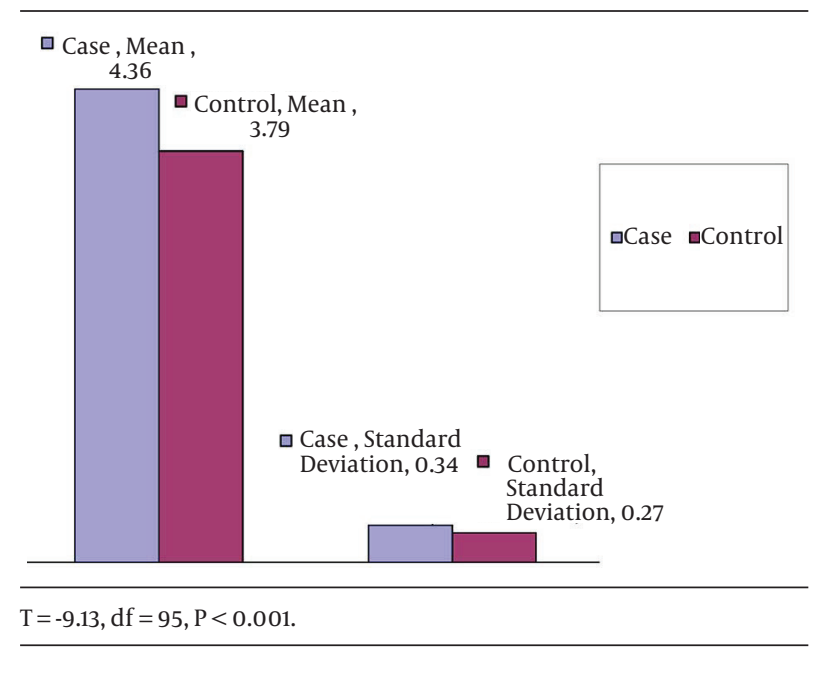

Figure 3. Comparing the Mean Latencies Time of Wave V of Auditory Brain Stem Evoked Response Between Right Ears of Case Group and That of the Control Group

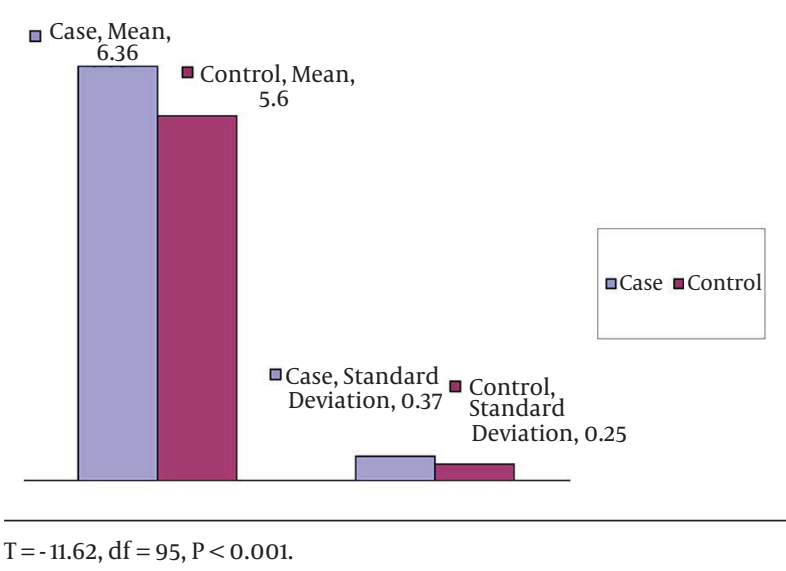

Figure 4. Comparing the Mean Inter-Peak-Intervals of Waves I-V of Auditory Brain Stem Evoked Response Between Right Ears of the Case Group and That of the Control Group

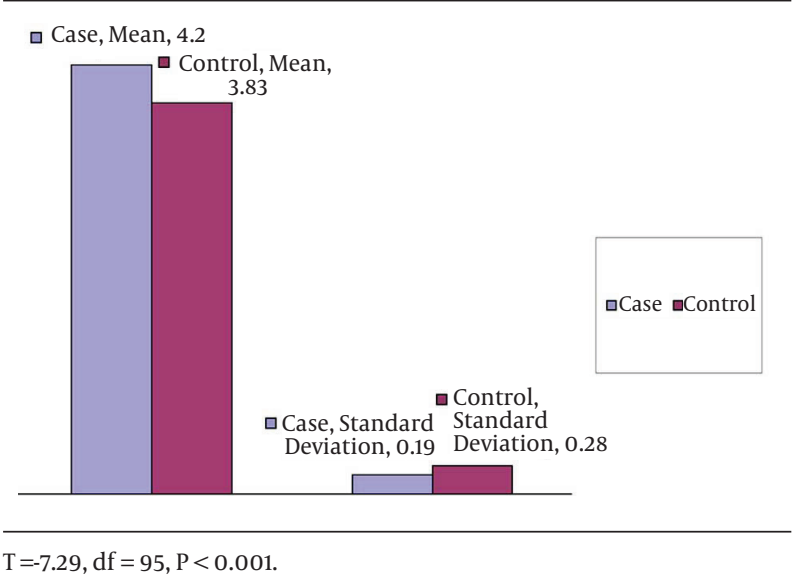


Figure 5. Comparing the Mean Inter-Peak-Intervals of Waves I-III of Auditory Brain Stem Evoked Response Between Right Ears of the Case Group and That of the Control Group

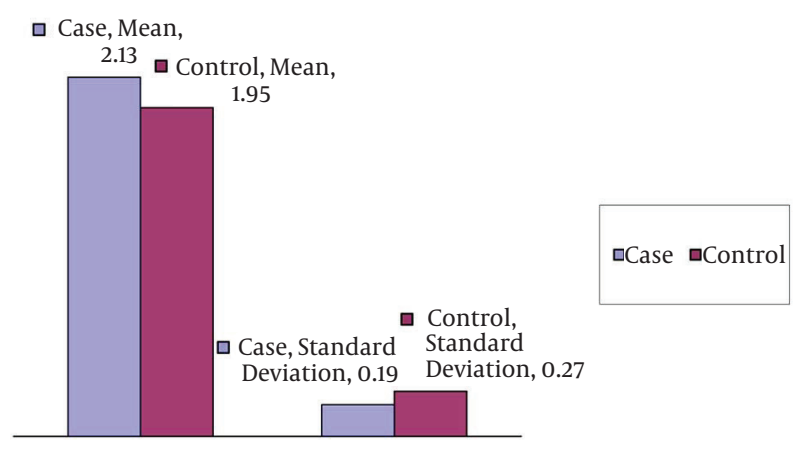

$\mathrm{T}=-3.70, \mathrm{df}=95, \mathrm{P}<0.001$

Figure 6. Comparing the Mean Inter-Peak-Intervals of Waves III-V of Auditory Brain Stem Evoked Response Between Left Ears of the Case Group and That of the Control Group

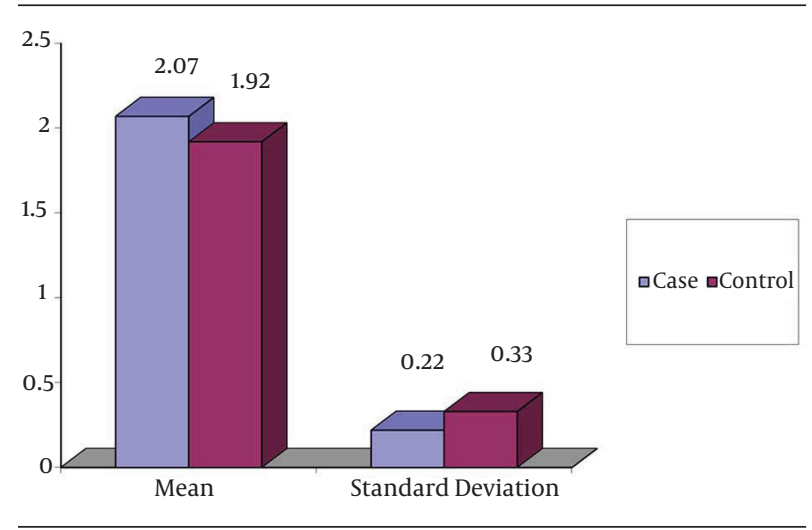

$\mathrm{T}=-2.52, \mathrm{df}=95, \mathrm{P}=0.013$.

According to the results in ABR, the mean latencies of various waves and mean inter-peak intervals were significantly higher in pathological hyperbilirubinemia compared to controls and there was a significant statistical difference between the two groups $(\mathrm{P}<0.001)$. Variables like gender, birth weight and Apgar score in one and five minutes, maternal age, number and type of delivery, and other variables were also considered (Table 3 ).

\section{Discussion}

ABR has been an effective method of assessing the auditory pathway and brainstem function in newborns and infants, recently recognized as a useful diagnostic tool in newborns $(5,10,11)$. In the present study, latencies of all the waves and intervals were significantly prolonged in patients with pathological hyperbilirubinemia compared with healthy controls, which showed affected VIII nerve and brain stem as well.
Neurotoxic effects of bilirubin on brainstem and auditory pathways are a confirmed fact $(1,5)$. In the study performed by Baradaranfar et al. 35 newborns with bilirubin levels more than $20 \mathrm{mg} / \mathrm{dL}$ were studied by ABR. Their results showed a high incidence of autonomic neuropathy/autonomic dysreflexia among hyperbilirubinemic babies and screening in this regard seems reasonable (9). Saluja et al.strongly suggested that auditory neuropathy spectrum disorder is a common manifestation of acute bilirubin-induced neurotoxicity in late preterm and term infants with severe jaundice (15). In a research by Liang and Xie, 176 ears in 88 newborns with hyperbilirubinemia were studied by ABR. They confirmed the toxicity effects of hyperbilirubinemia on the auditory nervous system. The waves III, V latencies, III-V and I-V interweave intervals of ABR were significantly different and prolonged in comparison with the latencies in the control group. The toxicity was related to the species and number of etiologies. The hyperbilirubinemia caused by G6PD dehydrogenase, infections, $\mathrm{ABO}$ incompatibility and hemolytic diseases is much more dangerous to the auditory system than breastfeeding jaundice. They reported that damages to the auditory nervous system could be reversible (16).

Table 3. Variables Like Maternal age, Number of Deliveries, Apgar Score in One Minute, Gender and Birth Weight in Control and Case Groups

\begin{tabular}{|c|c|c|}
\hline Variables & Mean \pm SD & PValue \\
\hline Maternal age & & 0.22 \\
\hline Control & $26.06 \pm 4.03$ & \\
\hline Case & $25.18 \pm 2.94$ & \\
\hline Number of deliveries & & 0.09 \\
\hline Control & $1.87 \pm 0.91$ & \\
\hline Case & $2.22 \pm 1.1$ & \\
\hline Apgar score in $1 \mathrm{~min}$ & & 0.12 \\
\hline Control & $8.55 \pm 0.5$ & \\
\hline Case & $8.39 \pm 0.49$ & \\
\hline \multicolumn{3}{|l|}{ Gender } \\
\hline \multicolumn{3}{|l|}{ Female, \% } \\
\hline Control & 57.1 & \\
\hline Case & 43.8 & \\
\hline Male, \% & & 0.132 \\
\hline Control & 42.9 & \\
\hline Case & 56.2 & \\
\hline \multicolumn{3}{|l|}{ Birth weight } \\
\hline \multicolumn{3}{|l|}{ Normal (> 2500 g), \% } \\
\hline Case & 59.2 & 0.932 \\
\hline Control & 58.3 & \\
\hline \multicolumn{3}{|l|}{$1500-2500 \mathrm{~g}, \%$} \\
\hline Case & 40.8 & \\
\hline Control & 41.7 & \\
\hline
\end{tabular}


In Sharma et al. study on 30 icteric newborns, the mean latency of waves and interwove intervals on the BAR records were prolonged in icteric babies compared to the control group, suggesting early bilirubin encephalopathy (17). Ahlfors and Parker concluded that increasing unbound bilirubin concentrations were associated with abnormal automated auditory brainstem response for jaundiced newborns, but not increasing the total bilirubin concentrations (18). A similar study strongly suggested the relationship between bilirubin peaks level and its behavior on neurodevelopment outcomes (19).

In a similar study, all the wave latencies and the I-V interval increased significantly, which were weakly correlated with the total serum bilirubin. Therefore, although the acute ototoxic effect of hyperbilirubinemia tends to be more significant at a higher rather than a lower level of total serum bilirubin, auditory impairment does not increase closely with the increase of bilirubin (20).

In the present study, we reported a high rate of hearing impairment among a high-risk population of newborns with severe or pathologic hyperbilirubinemia. Early diagnosis and treatment of hyperbilirubinemia is highly important for preventing hearing loss and all newborns with pathologic hyperbilirubinemia must be screened. ABR abnormalities may be transient in majority of patients, which significantly depends on the level of serum bilirubin and the duration of jaundice. In a similar study, the toxic effects of hyperbilirubinemia on the auditory brainstem pathway and neurodevelopmental status was transient (21).

The higher the bilirubin concentration, the higher the risk of impairments to the auditory system; but, most of the impairments are reversible (22). Before performing the hearing screening program in developed countries, only high-risk infants were evaluated for hearing screening, but over half of the cases were not diagnosed. While there is no establishment of a national screening program in Iran, according to the American Academy of Pediatrics (AAP) recommendation, performing hearing screening in high-risk newborns is necessary, including newborns with maternal illness during pregnancy, positive family history, intrauterine infections such as Torch syndrome, craniofacial malformations, birth weight less than 1500 g, prematurity, oxygen deprivation, respiratory problems, Apgar scores 0-4, 6-0 in the first minute and $0-6$ in the fifth minute, mechanical ventilation for five days or more, bacterial meningitis, treatment with autotoxin drugs, and sever hyperbilirubinemia. These infants may be normal in the initial screening, but need to continue periodic reviews, since delay in the development of hearing loss is discovered after six months to three years, and then stabilized screenings at appropriate intervals should be performed. As a result $A B R$ is a useful, noninvasive, cost-effective and radiation-free tool to detect neurodevelopment delays secondary to hyperbilirubinemia. Therefore, as national neonatal hearing screening in not yet established in
Iran, we recommend performing ABR for screening of bilirubin neurotoxicity in pathological hyperbilirubinemia and in all other cases of AAP recommendations as high risk newborns. Hearing screening may be normal in the initial evaluation and also toxic effects of hyperbilirubinemia may be transient; therefore, periodic reviews should be continued.

\section{Acknowledgements}

We gratitude all the nurses and staff of the Neonatal Intensive Care Unit (NICU) and the Department of Neurology, specially ABR center, and also Dr. Mehran Homam, the neurologist, and Mr. Sobhani. We are grateful to the mothers who volunteered in this study as well.

\section{Authors' Contributions}

Tooba Okhravi: acquisition of data, implementation the study, manuscript preparation, study conception, principal investigation, critical revision of the manuscript, manuscript preparation, and study supervision. Saeedeh Tarvij Eslami: contributions to conceive the study, principal investigation, critical revision of the manuscript for important intellectual content, study supervision, study conception, and manuscript preparation. Ali Hushyar Ahmadi: contributions to conceive the study, analysis and interpretation of data, and statistical analysis. Hossein Nassirian: participation in the study implementation and manuscript preparation and drafting of the manuscript. Reza Najibpur: contributions to conceive the study and submitting the article. All the authors read and approved the final manuscript.

\section{References}

1. Maheshwari A, Carlo WA. Digestive System Disorders. Kleigman RM, Stanton BF, Schor NF, Geme III JW, Behraman RE editors. Philadelphia: Saunders; 2011.

2. Gowen JR, Clarence W. Anemia and Hyperbilirubinemia. Marcdante KJ, Kleigman RM, Jenson HB, Behraman RE editors. Philadelphia: Saunders; 2011.

3. Mateo PC, Lee KS, Barozzino M, Sgro M. Management of neonatal jaundice varies by practitioner type. Can Fam Physician. 2013;59(8):e379-86.

4. Sgro M, Campbell D, Shah V. Incidence and causes of severe neonatal hyperbilirubinemia in Canada. CMAJ. 2006;175(6):587-90.

5. Thilo EH, Rosenberg AA. The Newborn Infant. 20th ed. Hay WW Levin MJ, Sondheimer JM, Deterding RR editors. United States of America: McGraw-Hill Company; 2011.

6. Najib KS, Saki F, Hemmati F, Inaloo S. Incidence, risk factors and causes of severe neonatal hyperbilirubinemia in the South of iran (fars province). Iran Red Crescent Med J. 2013;15(3):260-3.

7. Hemmati F, Saki F, Saki N, Haghighat M. Gilbert syndrome in Iran, Fars Province. Ann Saudi Med. 2010;30(1):84.

8. Bhutani VK, Johnson LH, Keren R. Diagnosis and management of hyperbilirubinemia in the term neonate: for a safer first week. Pediatr Clin North Am. 2004;51(4):843-61.

9. Baradaranfar MH, Atighechi S, Dadgarnia MH, Jafari R, Karimi G Mollasadeghi A, et al. Hearing status in neonatal hyperbilirubinemia by auditory brain stem evoked response and transient evoked otoacoustic emission. Acta Med Iran. 2011;49(2):109-12.

10. Abramovich S. Electric Response Audiometry in Clinical Practice.1st edPhiladelphia: Churchill Livingstone; 1990. 


\section{Okhravi Tet al.}

11. Picton TW, Taylor MJ, Durieux-S A. Brainstem Auditory Evoked Potentials in Infants and Children. 6 ed. Aminoff MJ editor. Philadelphia: Elsevier; 2012.

12. Brown CJ, Johnson TA. Electrophysiologic Assessment of Hearing. 15 ed. Flint PW, Haughey BH, Lund VJ, Niparko JK, Richardson MA Thomas Robbins K editors. United States of America: Elsevier Mosby; 2010.

13. Kaplan M, Wong RJ, Sibley E, Stevenson DK. Neonatal Jaundice and Liver Disease. 9 ed. Martin RJ, Fanaroff AA, Walsh MC editors. Philadelphia: Elsevier Saunders;; 2010.

14. Bhutani VK, Johnson L, Sivieri EM. Predictive ability of a predischarge hour-specific serum bilirubin for subsequent significant hyperbilirubinemia in healthy term and near-term newborns. Pediatrics. 1999;103(1):6-14.

15. Saluja S, Agarwal A, Kler N, Amin S. Auditory neuropathy spectrum disorder in late preterm and term infants with severe jaundice. Int J Pediatr Otorhinolaryngol. 2010;74(11):1292-7.

16. Liang Y, Xie XM. [Characteristics of auditory brain stem response in neonatal hyperbilirubinemia induced by different causes].
Zhonghua Er Bi Yan Hou Tou Jing Wai Ke Za Zhi. 2011;46(3):190-4

17. Sharma P, Chhangani NP, Meena KR, Jora R, Sharma N, Gupta BD Brainstem evoked response audiometry (BAER) in neonates with hyperbilirubinemia. Indian J Pediatr. 2006;73(5):413-6.

18. Ahlfors CE, Parker AE. Unbound bilirubin concentration is associated with abnormal automated auditory brainstem response for jaundiced newborns. Pediatrics. 2008;121(5):976-8.

19. Ip S, Chung M, Kulig J, O'Brien R, Sege R, Glicken S, et al. An evidence-based review of important issues concerning neonatal hyperbilirubinemia. Pediatrics. 2004;114(1):e130-53.

20. Jiang ZD, Chen C, Liu TT, Wilkinson AR. Changes in brainstem auditory evoked response latencies in term neonates with hyperbilirubinemia. Pediatr Neurol. 2007;37(1):35-41.

21. Chen WX, Wong VC, Wong KY. Neurodevelopmental outcome of severe neonatal hemolytic hyperbilirubinemia. J Child Neurol. 2006;21(6):474-9.

22. Xie X, Liang Y. [Responsibility of mismatch negativity in neonates with hyperbilirubinemia]. Lin Chung Er Bi Yan Hou Tou Jing Wai Ke Za Zhi.2011;25(1):23-7. 